\title{
Bayeux - Rue Saint-Floxel
}

$\mathrm{n}^{\circ} 3325$

\section{Grégory Schütz}

\section{(C) OpenEdition}

1 Journals

Édition électronique

URL : http://journals.openedition.org/adlfi/16862

ISSN : 2114-0502

Éditeur

Ministère de la culture

Référence électronique

Grégory Schütz, «Bayeux - Rue Saint-Floxel », ADLFI. Archéologie de la France - Informations [En ligne], Basse-Normandie, mis en ligne le 16 mars 2016, consulté le 19 avril 2019. URL : http:// journals.openedition.org/adlfi/16862

Ce document a été généré automatiquement le 19 avril 2019

(c) Ministère de la Culture et de la Communication, CNRS 


\section{Bayeux - Rue Saint-Floxel}

$n^{\circ} 3325$

\section{Grégory Schütz}

Lien Atlas (MCC) :

http://atlas.patrimoines.culture.fr/atlas/trunk/index.php?

ap_theme=DOM_2.01.02\&ap_bbox=-0.728;49.261;-0.676;49.294

1 Le diagnostic archéologique s'est déroulé dans le cadre du projet de construction d'une maison individuelle située rue Saint-Floxel à Bayeux. La parcelle étudiée, d'une superficie de $316 \mathrm{~m}^{2}$ se trouve à proximité immédiate de la nécropole gallo-romaine et du haut Moyen Âge, dite du Mont-Phaunus, au nord-est du centre-ville de Bayeux. L'intervention n'a livré aucune structure associée à la nécropole mais a permis néanmoins de mettre en évidence trois phases d'occupation allant de l'époque gallo-romaine à l'époque moderne (structures en creux, sols de travail et remblais).

2 La période antique est caractérisée par la succession de plusieurs niveaux stratifiés de chaux observés sur une superficie d'environ $15 \mathrm{~m}^{2}$. Ces derniers sont associés à des rejets charbonneux de foyers, à des remblais contenant de la chaux, des pierres et des blocs calcaires rubéfiés et, pour certains, en cours de transformation physico-chimique, ainsi qu'à des fragments de parois de fours vitrifiées. Ces différents éléments invitent à privilégier l'interprétation de ces couches comme des sols de travail liés à la production de chaux à proximité. Les rares indices permettant d'apporter quelques renseignements en termes de datation de cette phase courent entre le $\mathrm{I}^{\mathrm{er}}$ et le $\mathrm{III}^{\mathrm{e}} \mathrm{s}$.

3 Une seconde phase correspond à l'époque médiévale, et se traduit par la découverte de plusieurs fosses et trous de poteau qui viennent recouper les niveaux gallo-romains. Certains comblements ont livré des éléments de mobilier céramique attribuables à l'époque médiévale (sans doute du XIII ${ }^{\mathrm{e}}-\mathrm{XIV}^{\mathrm{e}} \mathrm{s}$ ).

4 Une troisième et dernière phase $\left(\mathrm{xv}^{\mathrm{e}} \mathrm{s} .-\mathrm{XVI}^{\mathrm{e}} \mathrm{s}\right.$. jusqu'au début du $\mathrm{xVIII}{ }^{\mathrm{e}} \mathrm{s}$.) a été mise en évidence sous la forme de remblais épais venant sceller les précédentes structures sur une épaisseur totale de près de $1,6 \mathrm{~m}$. 
INDEX

Index géographique : Basse-Normandie, Calvados (14), Bayeux

Index chronologique : Gallo-romain, Moyen Âge, Temps Modernes

operation Diagnostic (EV)

Mots-clés : fosse, stratigraphie, trou de poteau

\section{AUTEURS}

\section{GRÉGORY SCHÜTZ}

CG 14 